\title{
Monitoring glacier flow in Ny-Ålesund with a high temporal resolution ground-based interferometric-phased array radar
}

\author{
Rune Gundersen ${ }^{1,2}$, Richard Norland ${ }^{2} \&$ Cecilie Rolstad Denby ${ }^{1}$ \\ ${ }^{1}$ Faculty of Science and Technology, Norwegian University of Life Sciences, Ås, Norway; \\ ${ }^{2}$ ISPAS AS, Moss, Norway
}

\begin{abstract}
Monitoring glacier flow speed and calving rates is of interest for climate research, global sea-level studies and Arctic ship traffic. The research station in Ny-Ålesund, Svalbard, offers a unique location close to multiple glacier fronts. In this study, we explore the possibilities of permanent monitoring of glaciers in the Ny-Ålesund area using a ground-based interferometric radar with a significantly higher temporal resolution than what is achievable from satellites or mechanical scanning ground-based radars. Measurements were made from two different locations-Pynten and the Ny-Ålesund research station-located 5 and $15 \mathrm{~km}$ from Kronebreen glacier, respectively. The temporal resolution of the radar is flexible, and in this experiment is limited to five images per minute, providing data with high temporal resolution of glacier flow. We calculated a geo-located two-dimensional flow map of the glacier from the radar data, extracted glacier speed profiles and identified major calving onsets. This type of near real-time data may well be used with machine-learning techniques for more advanced monitoring systems. The radar measurements agree well with previous satellite measurements at lower temporal resolution. The observed mean flow of the Kronebreen glacier front varies across the glacier from around $0.4 \mathrm{~m} /$ day at the edges to $3 \mathrm{~m} /$ day in the central part. We identify and discuss possible improvements to the radar system and conclude that Ny-Ålesund is a well-suited location for radar monitoring of glacier flow velocities.
\end{abstract}

\section{Introduction}

The increased calving recently observed in Greenland and Antarctica is probably due to global warming (Scambos et al. 2017) and may reduce the volume of land-based ice, contributing to global sea-level rise and increased freshwater input to the ocean (Bamber et al. 2018; Box et al. 2018; Moon et al. 2018). It is reported that the calving rate of tidewater glaciers increases with ocean temperature (Luckman et al. 2015). Measurements of the temporal variation in glacier flow and the variation in calving rates could be valuable inputs for studying glacier dynamics. Direct measurements of glacier flow are often associated with high risk on account of motion, crevasses and calving activity, especially in the case of ocean-terminating glaciers, while remote sensing is a safe alternative.

\section{Keywords}

Terrestrial radar interferometry; phased array; Svalbard; remote sensing; atmosphere; glacier surface velocity

\section{Correspondence}

Rune Gundersen, ISPAS AS, P.O. Box 506, NO-1522 Moss, Norway. E-mail: rune.gundersen@nmbu.no

\section{Abbreviations}

G-B: ground-based

SAR: synthetic aperture radar $m$ a.s.l.: meters above sea level
Utilizing the phase of the received radar signal to detect and track displacements, interferometric radar measurements are an established remote sensing technique in geosciences for measuring surface deformations. Satellites carrying SAR could cover large areas with a relatively high spatial resolution. They have a surface displacement sensitivity of the order of millimetres when variations in the radio refractivity have been compensated for (Zebker et al. 1997). Because of the revisiting time (temporal resolution) of the satellite, geometric displacements between measurements could limit the accuracy of the measurements.

For detailed glacier flow studies, high spatial and temporal resolution is beneficial to avoid geometric decorrelation between consecutive measurements. A G-B radar can achieve this, as a G-B sensor is flexible when it comes to temporal resolution and instrument location, 
which controls spatial resolution. Studies published on the subject of G-B radar monitoring of glaciers use either interferometric real-aperture radar (Rolstad \& Norland 2009), G-B interferometric SAR (Rignot et al. 2002; Dematteis et al. 2017; López-Moreno et al. 2018) or G-B radar interferometer (Werner et al. 2008; Noferini et al. 2009; Strozzi et al. 2012; Voytenko et al. 2012; Voytenko et al. 2017; Xie et al. 2018). The mechanical scanning G-B radar interferometer antenna consists of one transmitting antenna and two or more receiving antennas, giving elevation as well as azimuth information. Both G-B interferometric SAR and G-B radar interferometer systems may provide better temporal and spatial resolutions than satellite-borne systems.

A potential disadvantage of G-B SAR and G-B radar interferometer systems in monitoring of geologic rapid-moving objects is the mechanical motion of antennas, which limits the temporal resolution; however, a way to combine spatial and high temporal resolution is to use an electronic scanning antenna, in other words a phased array antenna (Heinselman \& Torres 2011). A typical phased array antenna has the ability to change the angle of the antenna beam a few thousand times per second and achieve a higher effective temporal resolution because of the lower revisit time compared to a mechanically scanning antenna. Active phased-array antennas have been used in high-performance military and space systems for decades, but civilian use has been limited due to the high cost of development and manufacturing. In recent years, a number of integrated microwave circuits have been introduced that simplify design and cut manufacturing costs, making phased arrays radar systems a good alternative to G-B interferometric SAR and G-B radar interferometer. A phased array comprises a number of radiating elements whose phase and amplitude are controlled individually. The antenna beam is formed by shifting the phase of each element, altering the phasefront of the antenna and steering the antenna beam in the desired direction. The high temporal sampling of the radar makes it possible to extract detailed information about flow speed and calving, which may be of value in the study of glacier dynamics.

In this paper, we assess Ny-Ålesund as a potential location for permanent monitoring of glacier calving fronts using a G-B high temporal resolution interferometric phased array radar. The main objectives of this study are to compensate for the variations in radio refractivity and attenuation due to atmospheric variations; to find the spatial resolution achievable with the prototype radar antenna; and to determine the accuracy with which the glacier flow can be tracked. The potential for further optimization and development of the system is also discussed.
The Ny-Ålesund research facilities are located at Kongsfjorden, in the north-west Svalbard Archipelago, within a short distance of several glacier calving fronts. This research facility may be suited for long-term continuous calving observations by G-B radar since it is manned year-round. To evaluate pros and cons of Ny-Ålesund as a measurement site, we used Pynten as a reference site, which at the time of measurement was the closest safe position to use for measuring the glacier Kronebreen. The installation and operation of a permanent G-B radar in the Arctic region involves costly infrastructure and maintenance. If it is possible to achieve results of the same quality from Ny-Ålesund, it will significantly simplify the installation and lower the overall cost of operation and maintenance of the radar system, as it will not require an autonomous radar station. In this paper, we present the first results from monitoring the Kronebreen glacier with a high temporal and spatial resolution G-B radar with a phased-array antenna.

The tidewater glacier Kronebreen (Fig. 1) is about $8 \mathrm{~km}$ long and is fed by the Infant fonna glaciers and Holtedals fonna, which is the second largest ice cap in Svalbard. The mountain Colletthøgda limits the extent of Kronebreen to the north and the glacier Kongsvegen is the limit in the south. Terminating in Kongsfjorden, Kronebreen is one of the fastest-flowing glaciers in Svalbard (Lefauconnier et al. 1994). Results of January 2013 reported by Luckman et al. (2015) show a high flow of approximately $3 \mathrm{~m}$ /day in the central part of Kronebreen, slowing towards the edges and up-glacier, reaching a flow just below $1 \mathrm{~m}$ per day approximately $2 \mathrm{~km}$ from the terminus of the glacier. The flow speed of Kronebreen also varies inter-annually and with the seasons of the year (Kääb et al. 2005). From 1999 to 2002, the mean speed was $1.6 \mathrm{~m} /$ day at the centre of the glacier, with an inter-annual variability of $16 \%$. In another study, the summer maximum in the central part of the glacier was $2.1 \mathrm{~m} /$ day in June and July 2011 , and $3.2 \mathrm{~m} /$ day in July and August 2013 (Schellenberger et al. 2015).

The Norwegian University of Life Sciences and the company ISPAS AS have measured the flow of the Kronebreen glacier with an interferometric real-aperture radar yearly between 2007 and 2010 (Rolstad \& Norland 2009). The measurements in 2007, 2008 and 2010 were conducted from Pynten $\left(78^{\circ} 89^{\prime} \mathrm{N}, 12^{\circ} 34^{\prime} \mathrm{E}\right)$, approximately $4 \mathrm{~km}$ from the front of Kronebreen, and in 2009 from Ny-Ålesund, $13 \mathrm{~km}$ from the front of Kronebreen (Fig. 1). The sampling rate of the radar was approximately one measurement per second, yielding a high temporal resolution. However, this system does not give spatial data since it provides no cross-range information. During these campaigns, data were acquired from the central part of the glacier, from the front of the glacier 


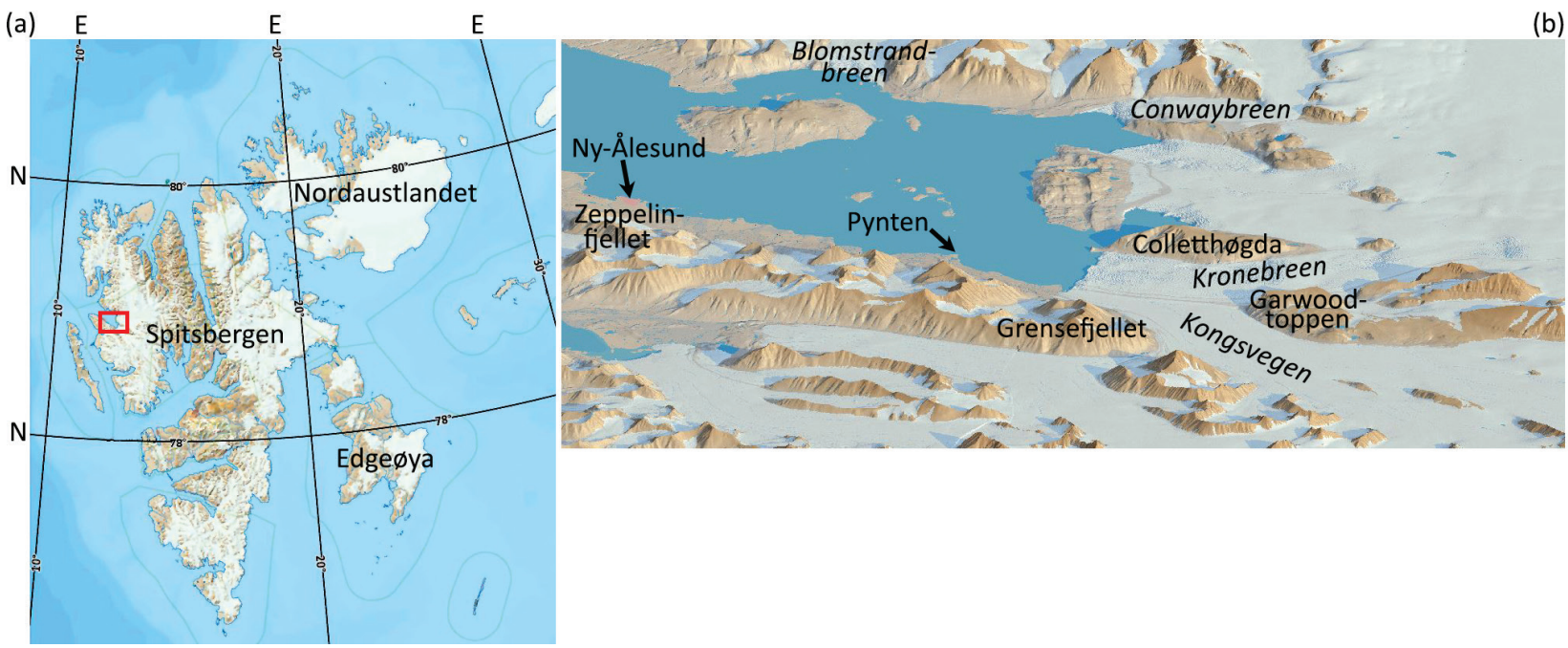

Fig. 1 (a) Location of the study area in Svalbard; (b) three-dimensional map of the fjord Kongsfjorden. Maps modified from Toposvalbard, Norwegian Polar Institute (retrieved from https://toposvalbard.npolar.no/ on 13 November 2019).

and from a few hundred metres up-glacier. The speed of the glacier front was measured at about $4 \mathrm{~m} /$ day, slowing to about $1 \mathrm{~m} /$ day $400 \mathrm{~m}$ up-glacier.

\section{Radar theory and system description}

In this section, we introduce some of the properties of the radar system and how the data could be used to extract information about glacier flow.

\section{Spatial resolution in range and cross-range}

The radar's ability to distinguish two targets in distance depends on the radar's range resolution, which is governed by the bandwidth $B W$ of the transmitted radar signal (Levanon 1988):

$$
\Delta R=\frac{c_{0}}{2 B W},
$$

where $c_{\mathbf{0}}$ is the speed of light. The range resolution of the radar $\Delta R$ remains constant regardless of the distance from the radar. However, the area of the rangecells increases with distance (see Fig. 2).

The cross-range or azimuth resolution of the radar is determined by the physical dimension of the antenna $L$ and the distance $R$ between the radar and the target (Levanon 1988):

$$
\Delta R_{\mathrm{cr}}=\frac{\lambda}{L} R
$$

where $\lambda$ is the wavelength of the transmitted radar signal. We note from Eqn. 2 that for a real aperture antenna the cross-range resolution declines linearly with distance from the radar (see Fig. 2).

\section{Interferometric radar measurements}

Interferometric radar measurements use the phase $\varphi$ of the reflected electromagnetic wave to derive information from the reflecting object. The phase is a function of the distance from the radar to the target (Chen $\delta$ Zebker 2002):

$$
\varphi=\frac{4 \pi}{\lambda} R
$$

where $\varphi$ is the observed relative phase, which is ambiguous in the interval $[-\pi, \pi]$, and because of this ambiguity, the absolute distance $R$ cannot be determined from $\varphi$. Hence, the maximum unambiguous range depends on the wavelength of the radar signal and is

$$
\left|\Delta r_{\max }\right|=\frac{\lambda}{4}
$$

Let the complex representation of the received radar signal be $z=A e^{i \varphi}$ If we have two reflections represented by the complex numbers $z_{1}$ and $z_{2}$, then the interferogram is

$$
z_{1} z_{2}^{*}=A_{1} A_{2} e^{i\left(\varphi_{1}-\varphi_{2}\right)}
$$

where ${ }^{*}$ is the complex conjugate of $z_{2}$. If the two measurements $z_{1}$ and $z_{2}$ are of the same target obtained at different times, any change in phase of the target reveals any temporal changes in distance between the radar and the target. 


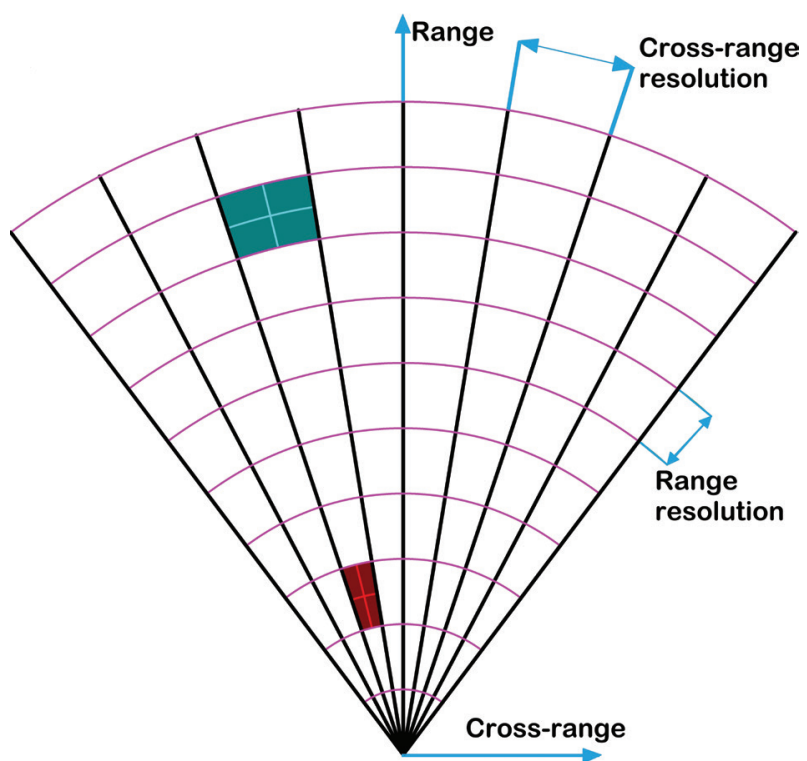

Fig. 2 An illustration of the range and cross-range resolution of the radar system used. The range-resolution is indicated by the magenta-coloured concentric arcs; note that the range resolution does not change with distance from the radar. The black lines indicate the cross-range resolution, which decreases linearly with distance from the radar indicated by the red and the cyan-coloured squares. The area bound by the black and magenta lines in Fig. 2 is the smallest area uniquely resolvable by the radar, referenced to as a pixel.

The interferometric phase $\varphi$, which is $\varphi_{1}-\varphi_{2}$ is the sum of multiple effects

$$
\varphi=\varphi_{d}+\varphi_{a}+\varphi_{n}+2 \pi n
$$

where $\varphi_{d}$ is the phase due to the displacement of the target, $\varphi_{a}$ is the phase due to atmospheric delays, $\varphi_{n}$ is the phase noise due to the radar hardware and $2 \pi n$ is the integer phase ambiguity. To unambiguously unwrap the phase of the interferogram, the right-hand sum in Eqn. 6 must be less than $\lambda / 4$ (Eqn. 4). Apart from using a radar with a low internal noise factor, the only parameter we can control to keep the phase shift $\varphi$ below $\lambda / 4$ is the time between measurements or the pulse repetition interval (PRI) of the radar. As $\varphi_{d}$ depends on the target's displacement between measurements, reducing the time between measurements linearly reduces the phase shift. Hence, a high PRI is desirable to avoid phase unwrapping ambiguities and make the radar system more noise-tolerant.

The maximum unambiguous velocity of a target is

$$
\left|v_{\max }\right|=\frac{\lambda}{4 \cdot P R I}
$$

The propagation speed of electromagnetic waves through the atmosphere varies with humidity, temperature and pressure. This is a temporal and spatial variation referred to as the index of refraction $\Delta n$, which affects the interferometric phase (Zebker et al. 1997):

$$
\varphi_{a}=\frac{4 \pi}{\lambda} \Delta n R
$$

Variation in the radio refractivity could be estimated from meteorological data or measured by monitoring the temporal variation in distance between the radar and a stationary target in the measurement scene (Gundersen et al. 2018a). This can partly eliminate variation in $\varphi_{a}$.

\section{Motion tracking}

Interferograms are calculated per pixel for consecutive data image pairs (Eqn. 5). The temporal stability or coherence of the amplitude is used as the selection criterion. The coherency is estimated as a moving average of $n$ observations per pixel as (Hanssen 2002):

$$
\hat{\gamma}=\left|\frac{\sum_{i=1}^{n}\left(z_{1} z_{2}^{*}\right)}{\sqrt{\sum_{i=1}^{n}\left|z_{1}\right|^{2} \sum_{i=1}^{n}\left|z_{2}\right|^{2}}}\right|
$$

Only the pixels with a coherence above a cut-off value are used and their phase is tracked, and the displacement is cumulatively added image-by-image. A cut-off value of $\hat{\gamma}>0.55$ is used, as reported by Berardino et al. (2002) to assure statistical significance of the measured phase. The coherence is calculated using a moving average and, depending on the coherence of the pixel, it is dynamically added or removed from the result. The corrections for variations in the radio refractivity are applied based on the measured temporal phase of a selected fixed point. To track the motion of the glacier, the phase from the selected points is unwrapped. If there are any unwrapping errors, that is to say jumps in phase above $\pm \lambda / 4$, the pixel is excluded from the result.

\section{Data organizing}

The radar data collected are organized in three dimensions. The first dimension is the down-range, where data are collected from a minimum to maximum radar range with a resolution equal to the radar range resolution (Eqn. 1). The second dimension is the cross-range, where data are collected per angle with an angular step resolution set by the radar. The effective cross-range resolution is limited by the $3-\mathrm{dB}$ antenna beam width, that is , the physical dimension of the antenna (Eqn. 2). The two dimensions give us a two-dimensional array of data in down-range and cross-range, referred to as data image. 


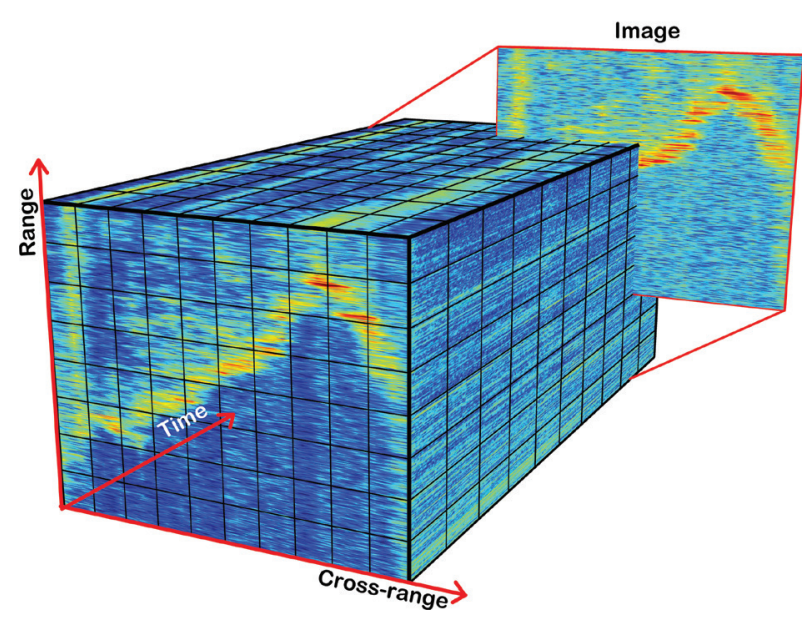

Fig. 3 Illustration of how the data collected by the radar are organized. The two-dimensional array of range and cross-range data makes an image of a backscatter. The time between two images is the revisit time of the radar, that is to say, the temporal resolution.

The third dimension is the temporal collection of data images. Figure 3 is an illustration of the organization of the collected radar data.

\section{Geometry of the measurements}

A reflecting point on the glacier is visible over an angle at least equal to the beam width of the antenna (Fig. 4). This means that a reflection point follows the radii equidistant to the radar and not a rectilinear grid. As the radar scans the glacier, the geometry between the radar's antenna beam and the front of the glacier changes (Fig. 4).

The measured glacier flow is underestimated except from where the flow direction of the glacier is perpendicular to the direction of the radar's antenna beam. All results presented in this paper are compensated for the scan-induced change in geometry.

Major reflections from the glacier are from the front and the many elevation steps at the crevasses. Because of the low angle between the incident electromagnetic field and the surface of the glacier, few reflections are noticed (Fig. 5).

\section{Measurement resolution set-up and radar parameters}

Here we present and compare the spatial and temporal resolution of the measurement set-up for the two locations used during the campaign. The first measurements were from Ny-Ålesund and the second from the headland Pynten, closer to the glacier. We also describe temporal resolution and radar parameters.

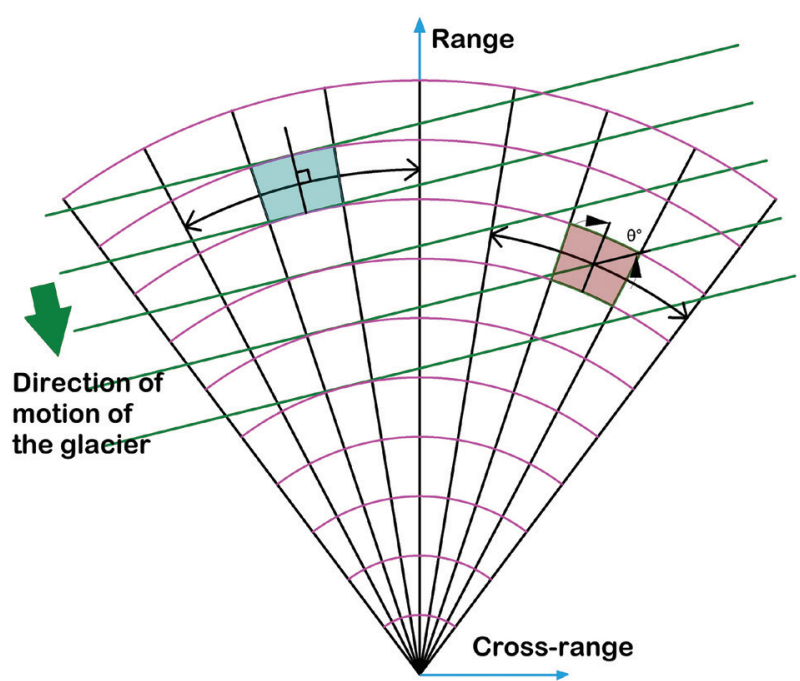

Fig. 4 An illustration of the radar-glacier measurement geometry showing how a reflection from the glacier may appear in the radar data. The green arrow indicates the direction of motion of the glacier and the green lines indicate the orientation of the glacier front with respect to the location of the radar. The magenta-coloured lines represent the radar range-resolution, that is, constant range from the radar. Two reflection points are illustrated by blue and red squares. To calculate the actual flow of glacier, the measured speed must be adjusted by the corresponding offset angle between the direction of the radar's antenna beam and the flow direction of the glacier for all scanned angles.

\section{Radar parameters}

The radar used is a coherent radar, which means we measure both amplitude and phase of reflections. The radar operates at a centre frequency of $15.85 \mathrm{GHz}$ (Ku-band). It has full polarimetric capability, that is, the polarization of the transmitted and received signals is independently programmable. This radar is capable of scanning electronically the antenna beam in horizontal plane from -50 to $+50^{\circ}$ with a pulse repetition frequency of up to $2 \mathrm{kHz}$, giving high temporal and spatial resolution with displacement-monitoring capability at a sub-millimetre level. Major radar parameters are listed in Table 1.

The cross-range resolution of the radar is $3^{\circ}$ (Eqn. 2) and should not be confused with the electronic step-size of the antenna. The angular step-size of $0.1^{\circ}$ is analogous to oversampling, in this case giving a maximum of 30 samples per real-aperture resolution.

\section{Measurement set-up}

Measurement geometry at Pynten: spatial resolution. Pynten $\left(78.89^{\circ} \mathrm{N}, 12.34^{\circ} \mathrm{E}\right)$ is located approximately 9 km east-south-east of Ny-Ålesund (Fig. 6). The distance from the radar to the front of the glacier was measured by 


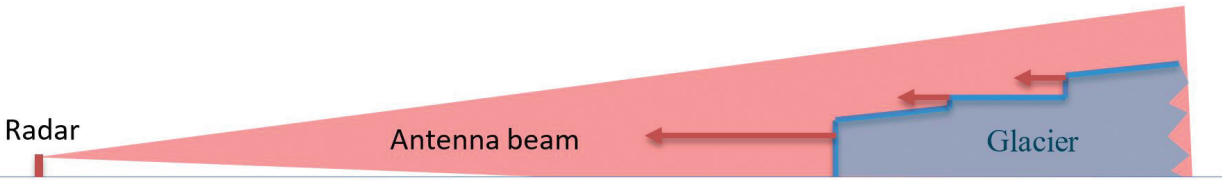

Fig. 5 An illustration of the measurement set-up. The radar is located on the left and a schematic view of the glacier is on the right. The major reflections are from the front of the glacier and from the elevation steps at the crevasses.

Table 1 Radar parameters.

\begin{tabular}{ll}
\hline Radar parameters & Parameter \\
\hline Centre frequency (GHz) & 15.85 \\
Maximum bandwidth (MHz) & 300 \\
Maximum pulse repetition frequency $(\mathrm{Hz})$ & 2000 \\
Maximum horizontal scan angle & $\pm 50^{\circ}$ \\
Polarization & $\mathrm{HH}, \mathrm{VV}, \mathrm{HV} \& \mathrm{HV}$ \\
Antenna 3-dB beam width & $3^{\circ}$ \\
Minimum scan step in azimuth & $0.1^{\circ}$ \\
Measurement uncertainty $(\mathrm{mm})$ & $<0.1(2 \sigma)$ \\
\hline
\end{tabular}

laser rangefinder and varied from 5675 to $6650 \mathrm{~m}$ from near to far end of the glacier front. The elevation of the radar was approximately $6 \mathrm{~m}$ a.s.l. The radar was directed against the centre of the front of Kronebreen, which gave a varying offset angle between the scan direction of the radar and the front of the glacier. The angle varied from approximately $1^{\circ}$ close to Colletthøgda to approximately $31^{\circ}$ at the crossing point between Kronebreen and Kongsvegen (see Fig. 7). We scanned the full width of the glaciers and recorded data in the range of 5 to $7 \mathrm{~km}$. Because of the offset angle between the radar and the front of the glacier, the up-glacier range recorded varied from $350 \mathrm{~m}$ at the southern end to $1325 \mathrm{~m}$ at the northern end. To cover the full width of the glacier, we scanned from -18 to $+25^{\circ}$ with an angular step size of $0.1^{\circ}$. The cross-range resolution was limited by the $3^{\circ}$ beam width of the radar antenna, which gives a cross-range resolution of approximately $315 \mathrm{~m}$. We scanned from left to right, that is from Colletthøgda across Kronebreen and Kongsvegen to Grensefjellet (see Fig. 7). An angular step size of $0.1^{\circ}$ equals a cross-range step resolution of approximately $10 \mathrm{~m}$ at $5.7 \mathrm{~km}$. The range resolution was $2 \mathrm{~m}$, that is, a radar bandwidth of $75 \mathrm{MHz}$. The total measured area was approximately $9 \mathrm{~km}^{2}$.

Measurement geometry at Ny-Ålesund: spatial resolution. The distance from $\mathrm{Ny}$-Ålesund to the front of Kronebreen was approximately $15 \mathrm{~km}$. The elevation of the radar was approximately $10 \mathrm{~m}$ a.s.l. The offset angle varied from approximately $14^{\circ}$ close to Colletthøgda to approximately $25^{\circ}$ at the crossing point between Kronebreen and Kongsvegen (see Fig. 8). To cover the full width of the glacier, we scanned from $-4^{\circ}$ to $+13^{\circ}$ (i.e., from left

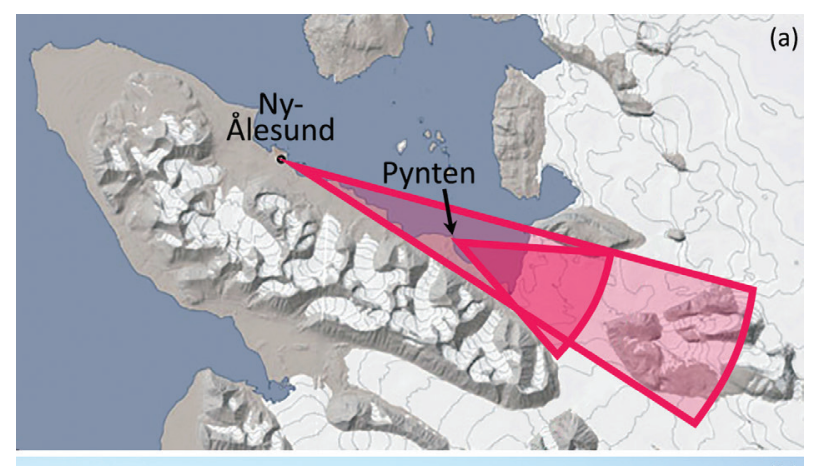

(b)

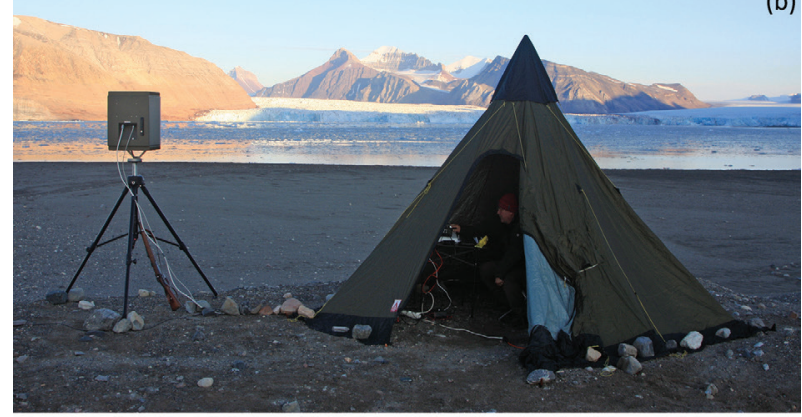

(c)

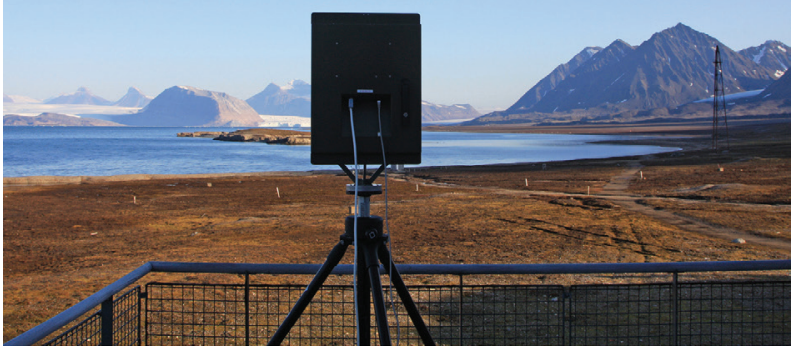

Fig. 6 (a) Map of the Ny-Ålesund area. The red wedges show the measured spatial coverage of the radar from Ny-Ålesund and Pynten. Images of the radar on location at (b) Pynten and (c) Ny-Ålesund. The map is modified from a map available at www.svalbardkartet.npolar.no.

to right) with an angle step size of $0.1^{\circ}$. The cross-range resolution was approximately $785 \mathrm{~m}$. Data were recorded from 14.5 to $29.5 \mathrm{~km}$ with a range resolution of $5 \mathrm{~m}$, that is, a radar bandwidth of $30 \mathrm{MHz}$. The total measured area was approximately $98 \mathrm{~km}^{2}$. Figure $6 \mathrm{c}$ shows an image of radar on location at Ny-Ålesund. 


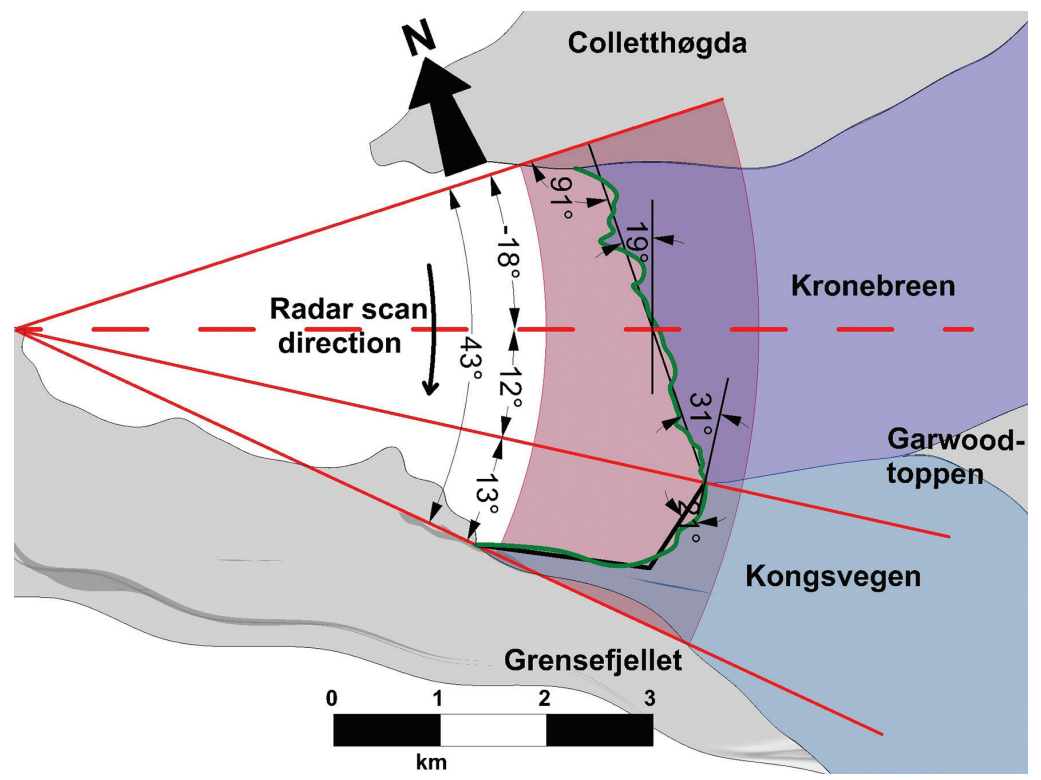

Fig. 7 Illustration of the measurement set-up at Pynten. The area illuminated by the radar is between the two outermost red lines. Only data within the red-coloured annular sector were saved. The black line drawn along the front of Kronebreen is the baseline used to calculate the offset between the direction of the radar waves and the glacier front and is taken to be perpendicular to the flow direction of the glacier. The glacier flows computed from the measurements are compensated by this offset angle. On the right-hand side, the offset is approximately $1^{\circ}$, and at the conjoining point between Kronebreen and Kongsvegen the offset is approximately $31^{\circ}$.

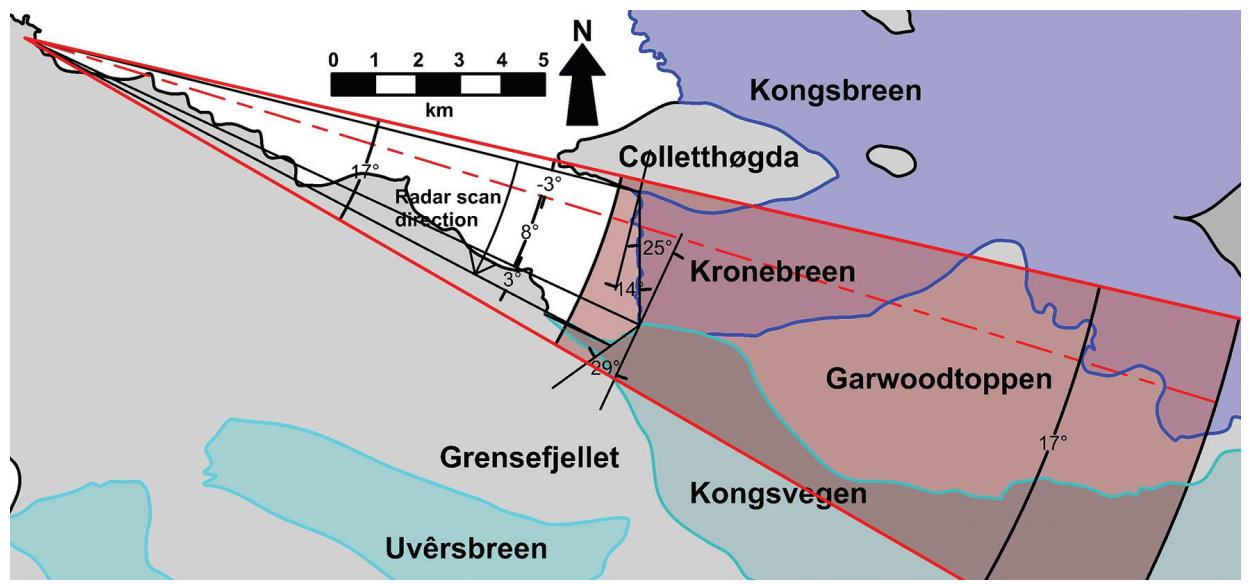

Fig. 8 An illustration of the measurement set-up at Ny-Ålesund. The area illuminated by the radar is between the two outermost red lines. The red dashed line indicates the zero angle of the radar antenna. Only the data within the red-coloured annular sector was were saved. The black line drawn along the front of Kronebreen is the baseline used to calculate the offset between the direction of the radar waves and the glacier front and is taken to be perpendicular to the flow direction of the glacier. The glacier flows computed from the measurements are compensated by this offset angle. On the northern end of Kronebreen, the offset angle is approximately $1^{\circ}$, and at the conjoining point between Kronebreen and Kongsvegen the offset is approximately $25^{\circ}$.

Temporal resolution. To reduce the amount of data collected, we scanned the glacier every 12 th second from Pynten and every 11 th second from Ny-Ålesund, giving a temporal resolution of approximately five images per minute. This trade-off between the image rate and the amount of data produced by the radar limits the maximum measurable unambiguous velocity to approximately $27.3 \mathrm{~m} /$ day (Eqn. 7). This should be fast enough 
to detect the onset of calving events. Previous measurements from Kronebreen (Rolstad \& Norland 2009) indicate that the maximum expected ice velocity, excluding frontal calving, is ca. $4 \mathrm{~m} /$ day.

A comparison between the two measurement set-ups is presented in Table 2 .

\section{Field tests}

The measurements from Pynten were made from 18:30 on 15 September 2017 to 08:30 on 16 September 2017. Weather data were collected at the radar site during the measurements. The measurements from Ny-Ålesund were made from 19:30 on 14 September 2017 to 09:30 on 15 September 2017. During the measurements, weather data were collected at the Norwegian Polar Institute's weather station at Pynten, located approximately two-thirds of the distance from the radar to the glacier front, and were made available to us.

\section{Results}

\section{Measurements from Pynten}

The maximum amplitude of the reflected energy from all the collected images for all range cells and angles was superimposed onto an image from the Sentinel-2 satellite (Fig. 9). The satellite image was acquired four days prior to the measurements and the results show good agreement between the maximum reflection measured by the radar and the outline of the front of the glacier from the satellite image (Fig. 9).

The front of the glacier is easily detectable from the radar amplitude data in Fig. 9. Reflections from the step pattern of the crevassed glacier surface are also clearly visible, making it possible to track the motion. The amplitude of the reflected energy from the front of the glacier is approximately $10 \mathrm{~dB}$ above the amplitude of the reflected energy from the crevasses. The distance to the front of the glacier determined with radar measurements correlates well with the distance measured by the laser rangefinder. The outline of the glacier front mapped by the radar also accords well with the glacier front found on the satellite image of the Ny-Ålesund area. This shows that we are able to identify the reflections from the glacier and map the radar data to the physical location on the glacier.
Path length variation and radio refractivity. To achieve high accuracy in the calculated displacement, corrections must be made for the temporal variations of radio refractivity. This could be done either by measuring variation in distance to a known fixed point or by calculating variation from meteorological data. Calculations established poor correlation between the variation calculated from the meteorological data and the variation measured to a fixed point on Colletthøgda. As a result, all path lengths were corrected according to the temporal variation of the fixed point. The variation in path length between the radar and the fixed point during the measurement reached a maximum of $\pm 6 \mathrm{~mm}$.

Flow speed of the glacier. The pixel-wise flow speed of the glacier was calculated using all collected images. The maximum flow speed recorded during the measurements was superimposed onto a satellite image from the Sentinel-2 satellite, and is presented in Fig. 10 .

Figure 10 shows how the speed varies across the glacier. The highest flow observed is along the front in the central part of Kronebreen, decreasing towards the edges and up-glacier, which accords with the results of previous measurements (Rolstad \& Norland 2009). The blue-coloured areas indicate high flow rates, which probably correspond to calving onsets or the rotational motion of large blocks of ice. Kongsvegen depicted little motion during the measurements. Figure 11 shows the accumulated measured flow of Kronebreen in increments of $2 \mathrm{hr}$.

Figure 11 shows the measured flow of Kronebreen at selected time intervals: (a) $2 \mathrm{hr}$, (b) $4 \mathrm{hr}$, (c) $6 \mathrm{hr}$, (d) $8 \mathrm{hr}$, (e) $10 \mathrm{hr}$ and (f) $12 \mathrm{hr}$. All points are selected based on their temporal stability with a coherence $\gamma=0.75$.

On account of the high spatial and temporal resolution of the radar, detailed time-displacement profiles and rangedisplacement information are available for detailed analysis. Figure 12 shows time-displacement profiles for a radar scan angle of $-2.1^{\circ}$ in $20-\mathrm{m}$ increments from the front of Kronebreen.

The time-displacement profile in Fig. 12 shows the temporal variation recorded for the frontal zone of Kronebreen. The front is at a range of $5790 \mathrm{~m}$. An increase in displacement was observed from the beginning of the measurements until about $1 \mathrm{hr}$, and then displacement decreases. This indicates a calving onset or a rotational motion of a block of ice. Further up-glacier, the displacement is relatively linear.

Table 2 Comparison of two measurement set-ups.

\begin{tabular}{lcccccc}
\hline Location & $\begin{array}{c}\text { Height of } \\
\text { radar }(\mathrm{m} \text { a.s.l.) }\end{array}$ & $\begin{array}{c}\text { Angular } \\
\text { step size }\end{array}$ & $\begin{array}{c}\text { Radar-glacier } \\
\text { distance }\end{array}$ & $\begin{array}{c}\text { Range } \\
\text { resolution }\end{array}$ & $\begin{array}{c}\text { Spatial } \\
\text { resolution }\end{array}$ & $\begin{array}{c}\text { Temporal of } \\
1 \text { pixel/cell } \\
\text { resolution }\end{array}$ \\
\hline Pynten & $6 \mathrm{~m}$ & $0.1^{\circ}$ & ca. $6 \mathrm{~km}$ & $2 \mathrm{~m}$ & $315 \mathrm{~m}^{2}$ & $628 \mathrm{~m}^{2}$ \\
Ny-Ålesund & $10 \mathrm{~m}$ & $0.1^{\circ}$ & ca. $15 \mathrm{~km}$ & $5 \mathrm{~m}$ & $3927 \mathrm{~m}^{2}$ & $11 \mathrm{~s}$ \\
\hline
\end{tabular}




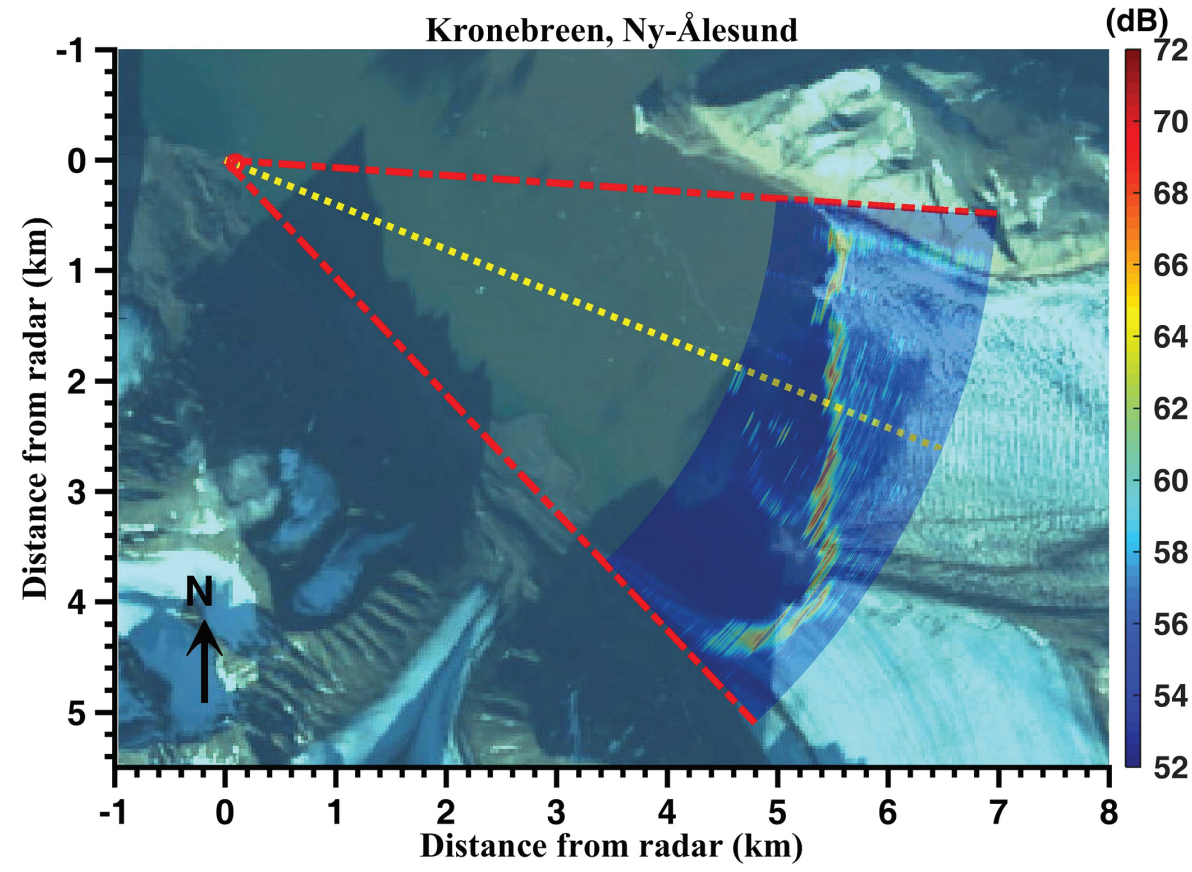

Fig. 9 Maximum measured reflected energy from Kronebreen and Kongsvegen glaciers superimposed on a satellite image from the Sentinel-2 satellite (image from the European Space Agency). Note that the satellite image is from 12 September 2017, while the measurements are from 15 September 2017 and 16 September 2017. The yellow line indicates the centre line of radar's look direction. The two red lines indicate the area mapped by the radar. The plot also shows the path of some icebergs floating just south of the centre line.

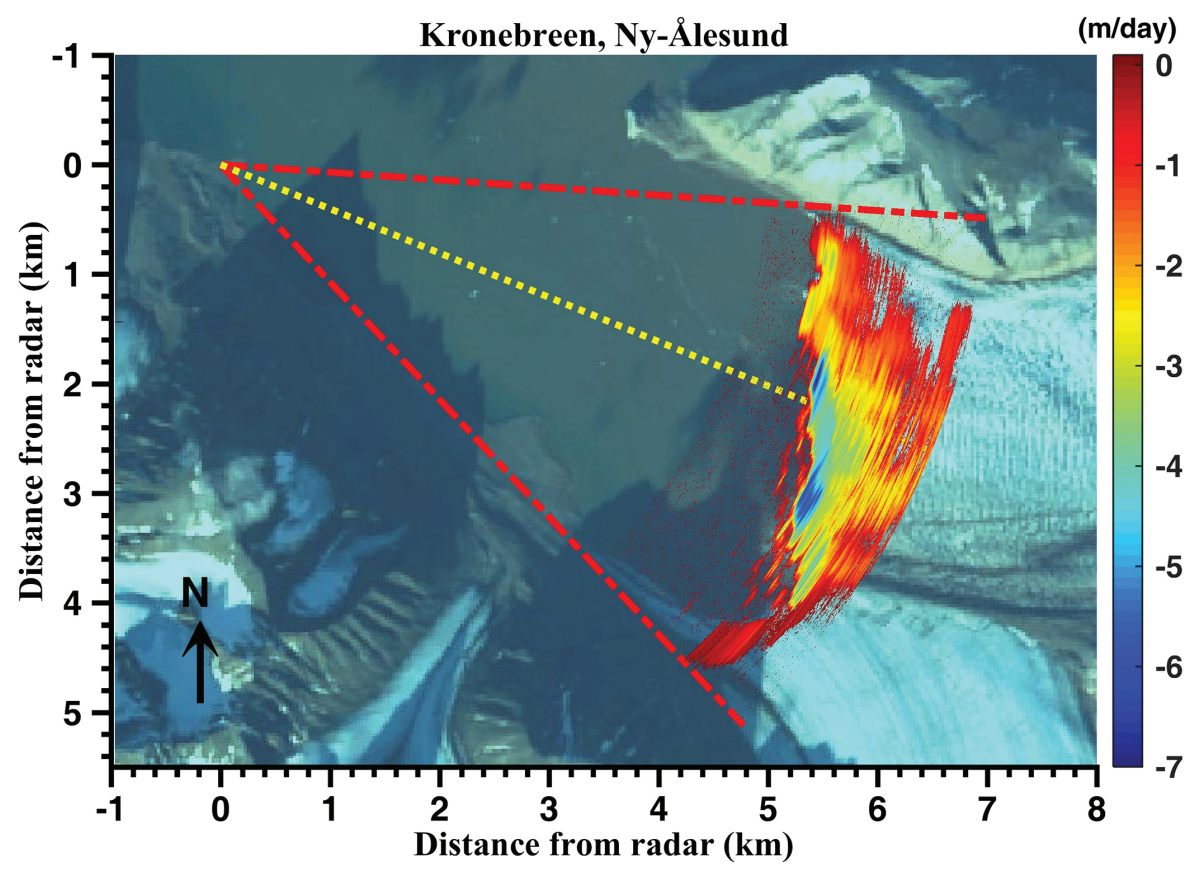

Fig. 10 Displacement of Kronebreen and Kongsvegen glaciers calculated using interferometry superimposed onto a satellite image from the Sentinel-2 satellite (image from the European Space Agency). The data presented are the maximum recorded flow using all images. The highest flow observed is in the central part of Kronebreen, along the front, where the maximum speed recorded is $7 \mathrm{~m} /$ day. This could be a calving onset, a rotational motion of a block of ice or a crevasse opening. 

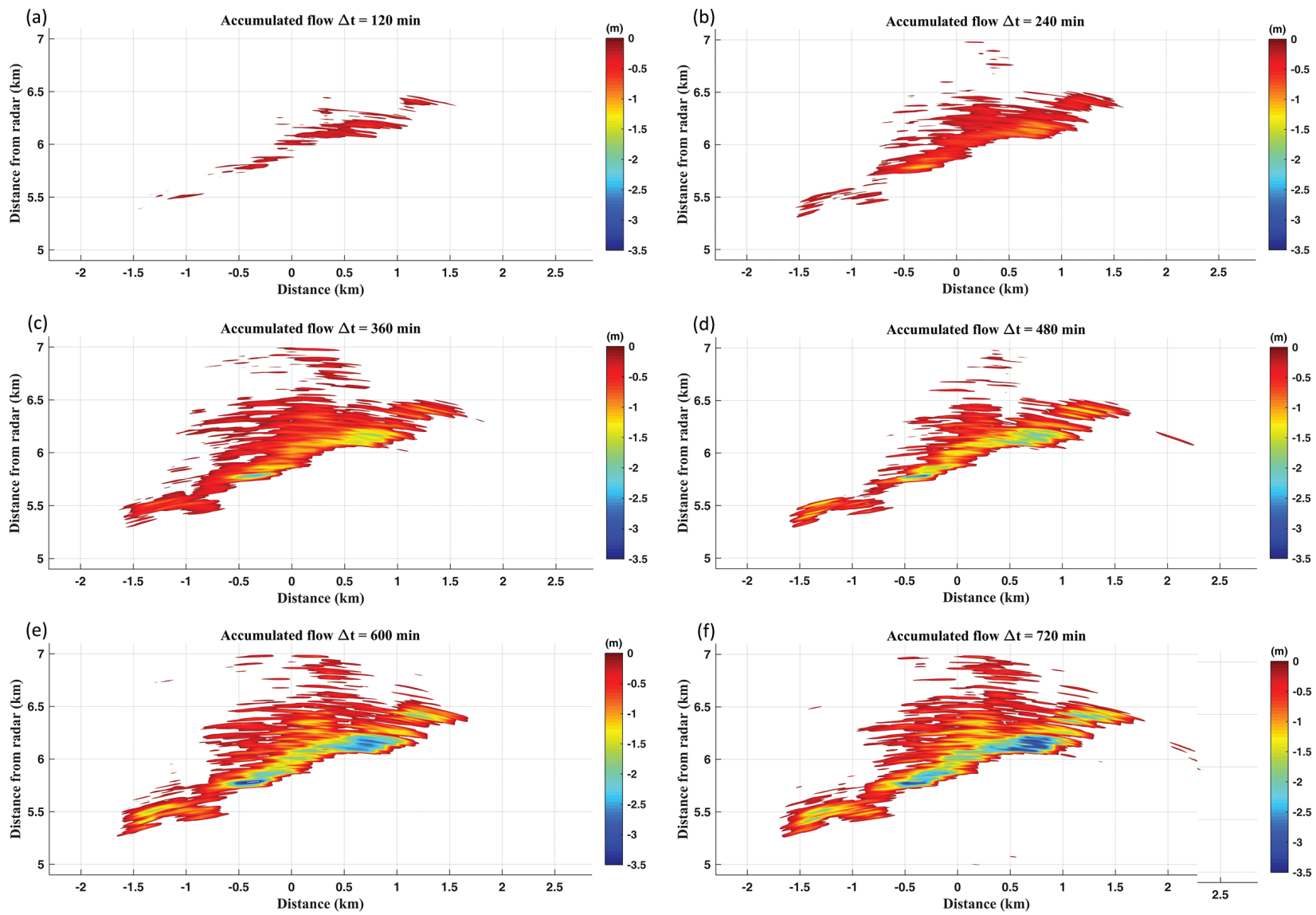

Fig. 11 Measured accumulated flow of Kronebreen as a function of time. Elapsed time: (a) $2 \mathrm{hr}$, (b) $4 \mathrm{hr}$, (c) $6 \mathrm{hr}$, (d) $8 \mathrm{hr}$, (e) $10 \mathrm{hr}$ and (f) $12 \mathrm{hr}$.

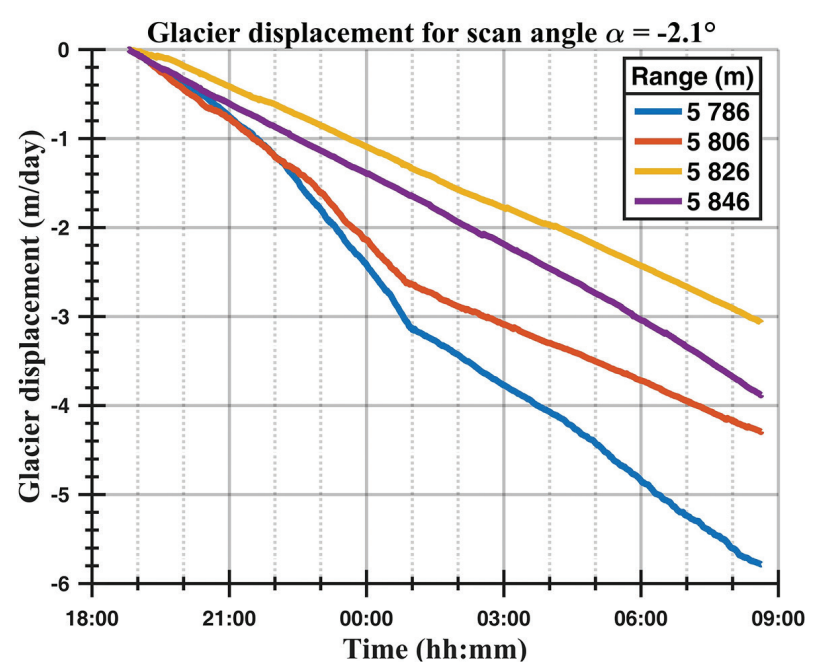

Fig. 12 Comparison of the measured displacement of Kronebreen for four different ranges in 20-m increments. This represents the displacement through one range cell. The blue line is the front of the glacier, $5786 \mathrm{~m}$ from the radar. At this range, we have an increase in the flow speed from 20:00 to $01: 00$. Then the displacement decreases. The same trend is visible at 5806-m range (red line), while at 5826-m range (yellow line) and 5846-m range (purple line) the displacement is close to linear during measurements.

\section{Measurements from $\mathrm{Ny}$-Ålesund}

Path length variation and radio refractivity. The radar measurement set-up in Ny-Ålesund covered the range of 14.5 to $29.5 \mathrm{~km}$ at Kronebreen. The intention was to find one or more stable reflection points on mountains and use them as a reference to correct the measurements of variations in radio refractivity. The four mountains covered were Colletthøgda, Garwoodtoppen, Pretender and Dronningfjella (Fig. 6). We found multiple points at Colletthøgda and Garwoodtoppen with stable amplitudes and phases. Variations in path lengths between the radar and these stable points during measurements are shown in Fig. 13, along with variations in path lengths due to radio refractivity calculated from the Norwegian Polar Institute's meteorological data.

Variation in radio refractivity calculated from the meteorological data indicated little resemblance to the measured path-length variation from two fixed points. The empirical model used assumed a homogeneous atmosphere and any deviations would lead to a drift between real and estimated variations. Additionally, meteorological data were only collected at a single point. Variations in path lengths 
between the radar and the fixed points during measurement reached a maximum of approximately $82 \mathrm{~mm}$ at Colletthøgda and approximately $88 \mathrm{~mm}$ at Garwoodtoppen. The mean variation in path lengths between the radar and these two points was used to correct the radio refractive-induced path-length variation for all data collected.

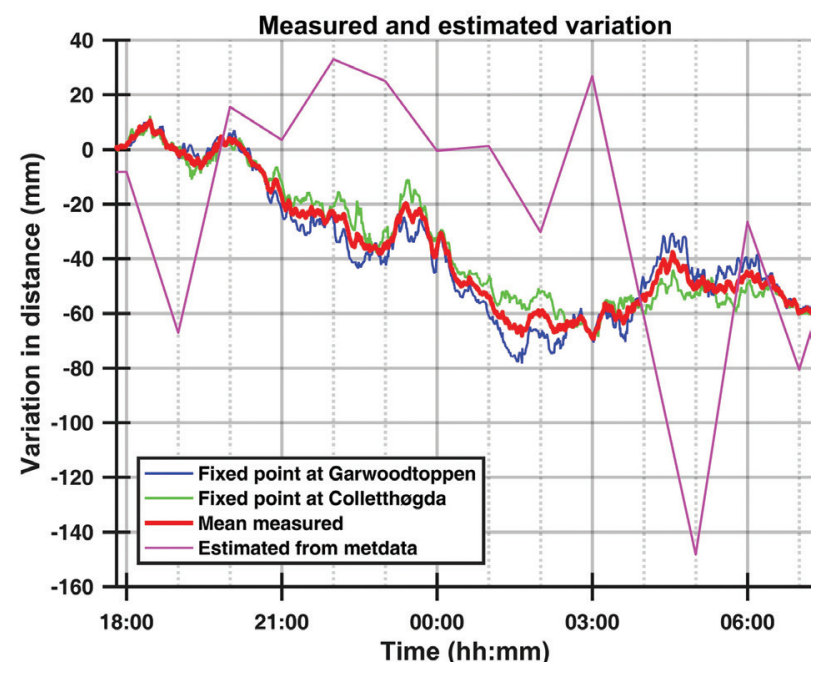

Fig. 13 Temporal variation of path length between the radar and two fixed points, one on Colletthøgda (green line) and another on Garwoodtoppen (blue line) during the measurements as a function of time. The red line is the mean value of the variation of two reference points. The purple line is the variation estimated from the meteorological data. The distances between the radar and the fixed points are 14835 and $19185 \mathrm{~m}$. The two fixed points are marked with a blue circle (Colletthøgda) and a green circle (Garwoodtoppen) in Fig. 14.
Flow speed of the glacier. The flow speed of the glacier was calculated using interferometry, and the results are superimposed on a satellite image of the Ny-Ålesund area (Fig. 14).

Similar to the results from Pynten, we observed the highest flow on the front and in the middle of the glacier, decreasing towards the edges and up-glacier. The selected reference points at Garwoodtoppen and Colletthøgda used for the correction of radio refractivity are marked in Fig. 14. Figure 15 shows the measured flow of Kronebreen in 2-hr increments.

Figure 16 shows time-displacement profiles for six range cells from 14,970 to $15,070 \mathrm{~m}$ from the radar for a fixed radar scan-angle of $0^{\circ}$ in 20 -m increments from the front of Kronebreen and up-glacier. The blue line shows how the flow increases during the hours before an event, which is believed to be a calving onset or rotational motion of a large block of ice. The second event is detected about $5 \mathrm{hr}$ later at a range of 15,030 m. The second event appears to take place $50 \mathrm{~m}$ up-glacier from the first event; however, it is believed to take place at the front of the glacier south of the first event. This is because of a combination of the radar-glacier measurement geometry and the cross-range resolution of the radar. First, the glacier front is not straight and is oblique to the radar line of sight. Second, the 3-dB beam width of the antenna equals a cross-range resolution of $785 \mathrm{~m}$ at $15 \mathrm{~km}$. This means we cannot distinguish between events more closely spaced than $785 \mathrm{~m}$ along the glacier front; consequently, we are likely to capture multiple events along the front of the glacier per scan angle.

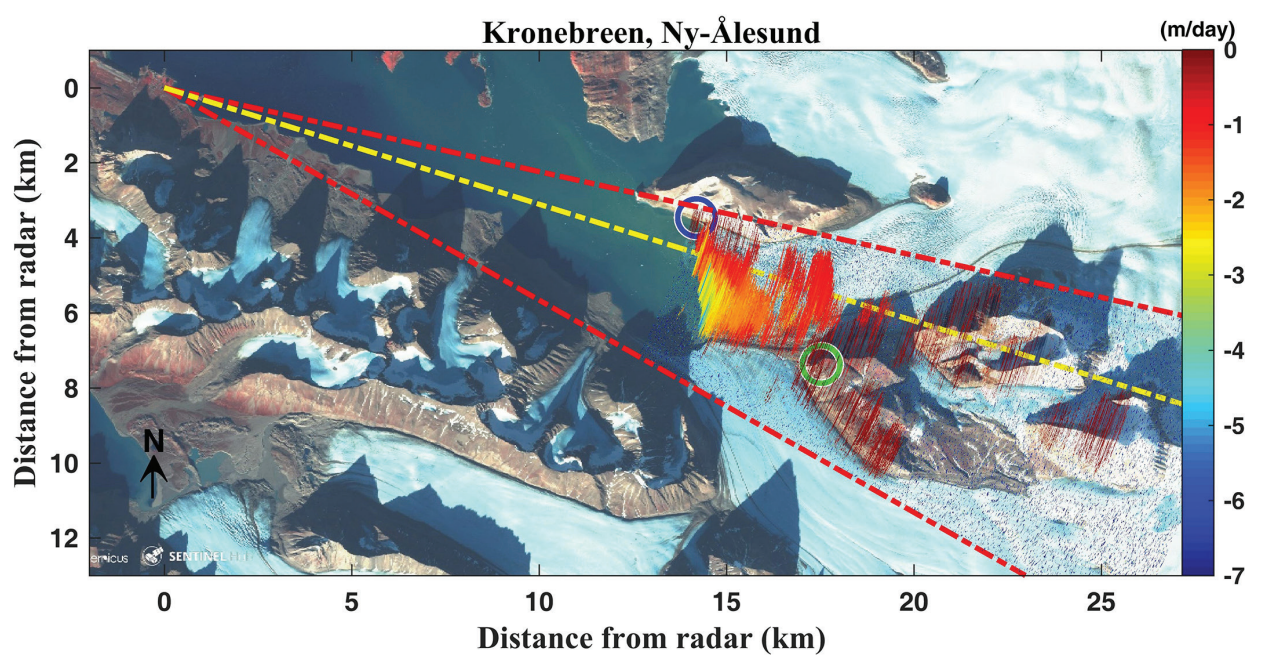

Fig. 14 Interferometric-calculated flow speed overlaid on a satellite image of scanned area. The blue and green circles indicate the location of two selected points used to correct variations in radio refractivity at Colletthøgda and Garwoodtoppen. The Sentinel-2 image taken on 13 September 2017 is from the European Space Agency. 

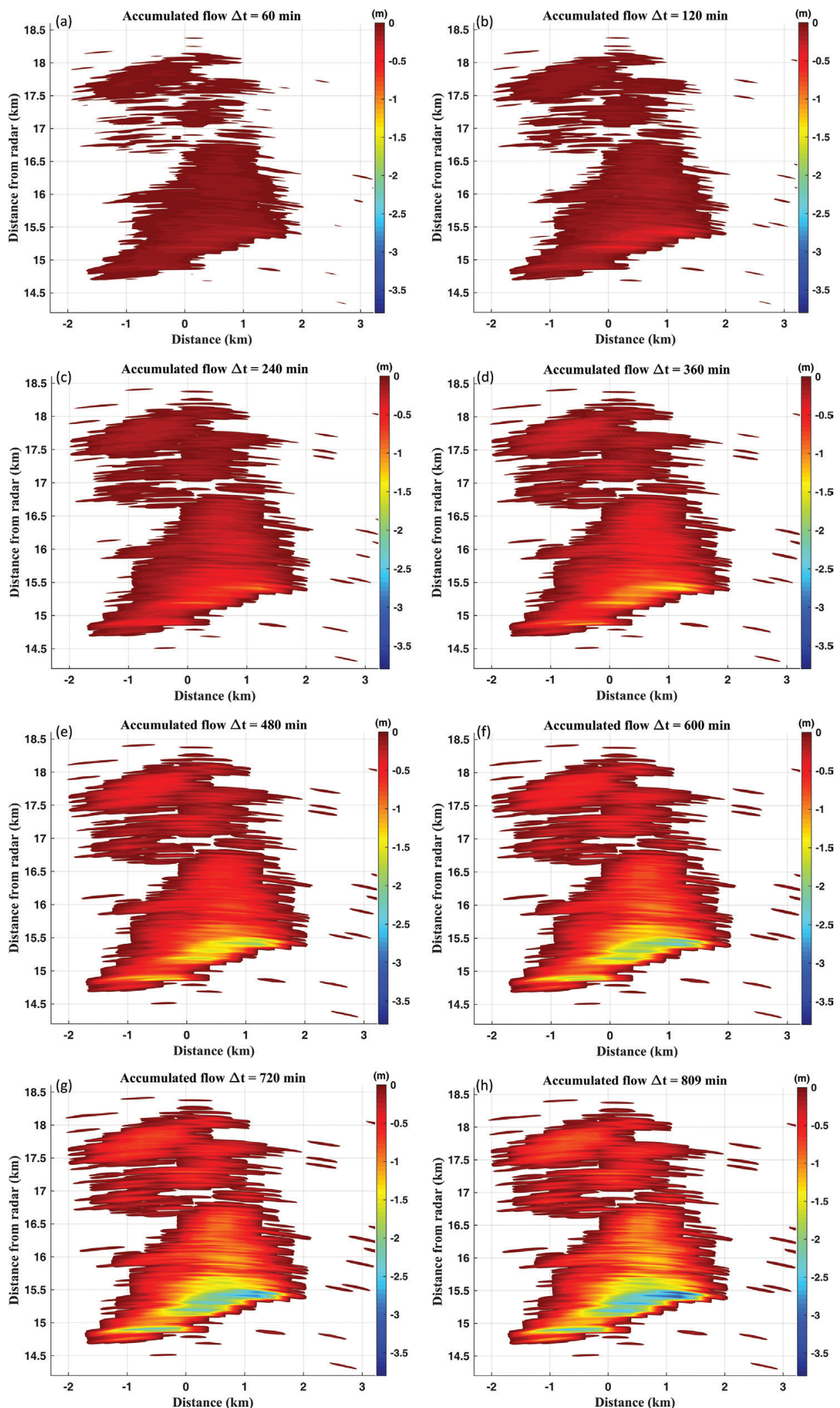

Fig. 15 Measured accumulated flow of Kronebreen as a function of time. Elapsed time: (a) 1 hr, (b) 2 hr, (c) 4 hr, (d) 6 hr, (e) $8 \mathrm{hr}$, (f) $10 \mathrm{hr}$, (g) $12 \mathrm{hr}$ and (h) $13 \mathrm{hr}$ and $29 \mathrm{~min}$. 


\section{Comparison of velocity measurements}

In this section, the measured flow speeds obtained from the two sites are compared. The difference in flow speed between the two locations is highlighted in Fig. 17.

The measurements from Pynten show a mean glacier flow from the glacier front and $300 \mathrm{~m}$ up-glacier varying

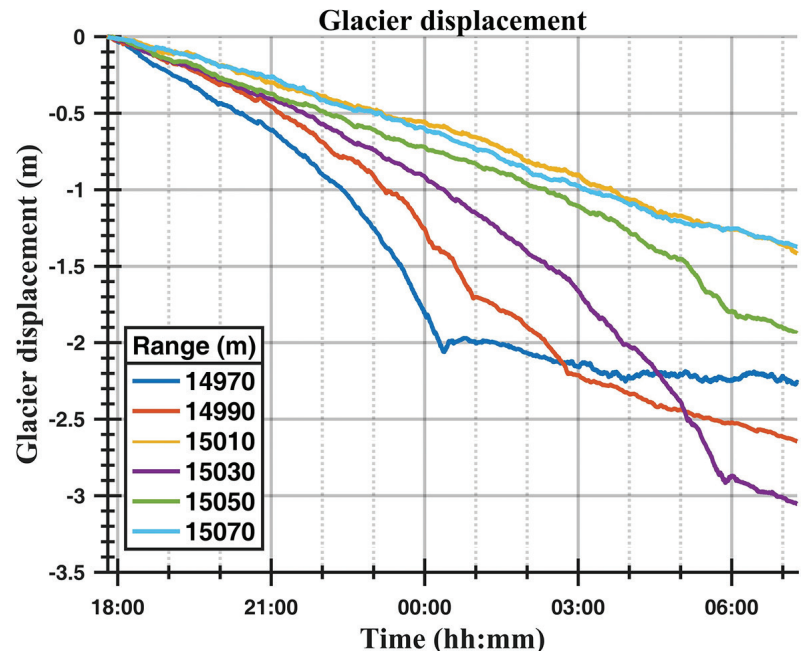

Fig. 16 Glacier displacement as a function of time for six different ranges in 20-m increments for the front of Kronebreen. This represents displacement through one range cell. The blue line is the front of the glacier $14970 \mathrm{~m}$ from the radar. For this cell, we have an increase in flow speed from the beginning of the measurements to 02:00. The same trend is visible at other cells, except for ranges 15010 and $15070 \mathrm{~m}$, which showed close to linear displacement during measurements. from 0.4 to $3 \mathrm{~m} /$ day (Fig. 17a), and measurements from Ny-Ålesund show a flow varying from 0.4 to $2.8 \mathrm{~m} /$ day (Fig. 17b) also for the first $300 \mathrm{~m}$. The flow speed is compensated for by the offset in the measurement geometry. The measurements were made from 14 to 16 September 2018, each measurement spanning approximately 12 and $13 \mathrm{hr}$

\section{Comparison with previous radar measurements}

We reprocessed the radar data acquired in 2008 (Rolstad \& Norland 2009) to compare it with the measurements made in 2017. The 2008 measurements were made from Pynten with a G-B real aperture radar operating at C-band with a pulse repetition frequency of approximately $1 \mathrm{~Hz}$. The measurements lasted for $92 \mathrm{hr}$. For reprocessing, a time span of $13 \mathrm{hr}$, which included a calving event, was chosen for comparison to the near $13 \mathrm{hr}$ of measurements in 2017 (Fig. 18).

Continuous visual observations of the glacier were made and all calving events were manually recorded and classified during the 2008 campaign (Chapuis et al. 2010). The visual data set confirmed a calving event at 18:00 represented by a red line in Fig. 18. If we compare the displacements indicated by the red line with the blue and red lines in Fig. 12 and the blue, red and purple lines in Fig. 16, we notice the same pattern. The pattern shows a period of accelerating motion before returning to a steady motion and is based on the pattern from 2008 believed to be calving events.
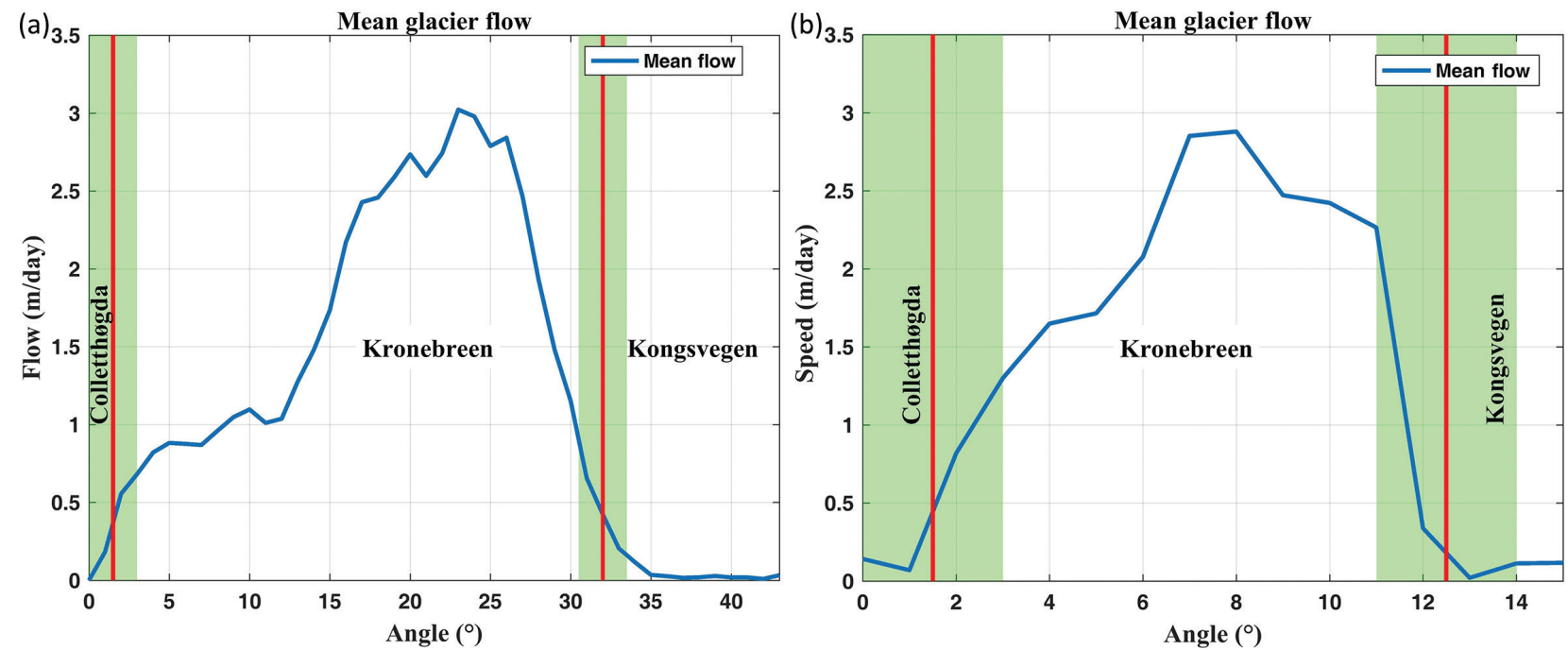

Fig. 17 Determined mean glacier flow as a function of radar scan angle. Note different spatial resolutions on the two horizontal axes of panels: (a) the mean flow for nearly $12 \mathrm{hr}, 15$ September 2017, from the front and $300 \mathrm{~m}$ up-glacier, measured from Pynten, and (b) the mean flow for nearly 13 hr on 14 September 2017, measured from Ny-Ålesund. From the left-hand side is Colletthøgda showing no motion. The data presented are mean values measured for all collected data images from both sites. 


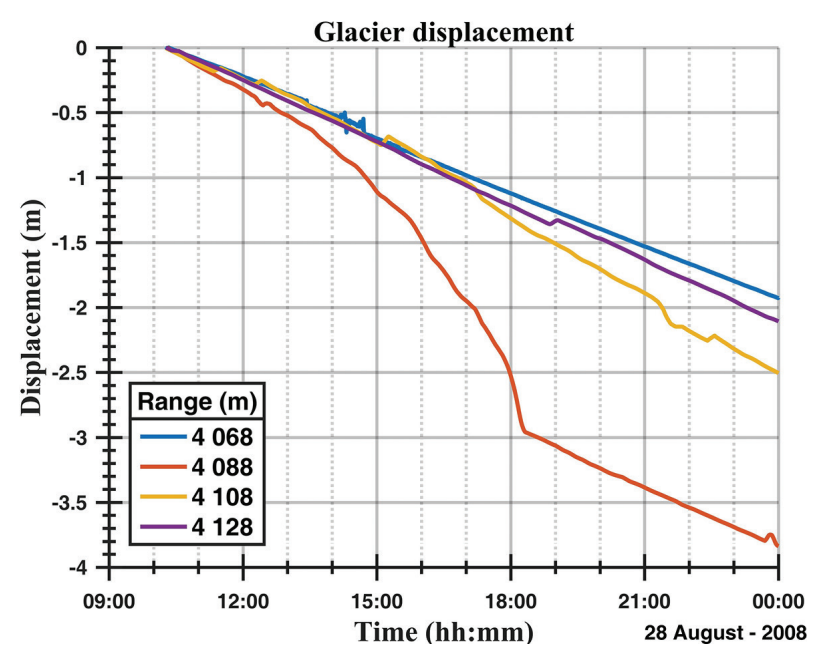

Fig. 18 Glacier displacement measured from Pynten in August 2008. The data are comparable with the data given in Fig. 12. Note that the glacier front has retreated more than $1.5 \mathrm{~km}$ from 2008 to 2017.

\section{Discussion}

The measurement experiment clearly demonstrates the potential of electronic scanning radar system to achieve a combination of high temporal and spatial resolution data of glacier flow. We were able to establish a detailed map of glacier flow during a short observation time. With the permanent installation of a monitoring radar, the diurnal, seasonal and inter-annual variations of glacier flow could be revealed. The influence of environmental effects such as tide, ocean and air temperature on calving rates could be analysed. However, some issues must be discussed further to develop an optimal monitoring radar system.

The attenuation of electromagnetic waves because of hydrometeors is still an unanswered question. The attenuation depends on the rate of precipitation, the path length of electromagnetic wave through the precipitation and the radar's operating frequency (Karamakar 2011). During the measurement campaign, there was stable dry weather and variations in attenuation could not be studied. In a study of short-range surveillance radars, the optimum operating frequency for ranges up to $20 \mathrm{~km}$ was found to be $15 \mathrm{GHz}$ (Baker \& Trimmer 2000). Measurement experiments at Ny-Ålesund should be conducted during varied weather conditions.

Coherence between consecutive measurements is required for interferometric calculations, as described in Eqn. 5. High temporal resolution is beneficial for high coherence of sequential measurements. In our measurement experiment, only data from reflection points fulfilling the selection criterion outlined earlier in connection with Eqn. 9 were included or excluded dynamically, depending on coherence. In addition, all range cells returning motion above $\lambda / 4$ between two successive measurements were discarded to reduce accumulation of errors. A benefit of high temporal sampling is the simplified phase unwrapping between consecutive images, as both geometrical displacements and atmospheric de-correlation will be small, preferably less than a quarter of wavelength. It should be investigated further whether the cut-off value (Eqn. 9) could be lowered with even higher temporal resolution of the measurement and whether the length of the moving average filter could be decreased.

Radio refractivity influences the velocity of electromagnetic waves and the best practical correction method must be determined and applied to the calculated interferometric glacier flow data. The measured and estimated variation in radio refractivity presented in Fig. 13 suggests that meteorological data from a single station are insufficient to make corrections for the variations in radio refractivity. The meteorological model assumes homogeneous atmospheric conditions along the path of electromagnetic waves. Local katabatic glacier winds (Kotlyakov \& Grosswald 2008) may create inhomogeneous conditions, and the spatial distribution of the calculated corrections may be inadequate for path length corrections. Fixed points with stable reflections on the mountains were assessed, as shown in Fig. 13, and used to compensate for variations in radio refractivity. All results are compensated for atmospheric variation measured at fixed points. With this method the variation in radio refractivity between the radar and the glacier is eliminated but not the variation across the glacier. The weakness of the applied method is therefore the assumption of a homogeneous atmosphere across the glacier, yielding a uniform correction of data. In the case of a permanent installation or a longer measurement period, it would be beneficial to have a reference reflector close to the glacier, giving a stable reference for corrections of variations in radio refractivity (Gundersen et al. 2018a) and a reflector close to radar for the self-monitoring of radar (Gundersen et al. 2018b).

Estimates of measurement uncertainty are based on relative observations of the distance to the fixed points on the mountains. We used the measured mean value from the two points to correct variation in radio refractivity, and the deviation from this mean value to the actual measured value is used as the estimated uncertainty of the calculated flow. From the measurements at Ny-Ålesund, the median deviation was found to be approximately $\pm 12 \mathrm{~mm}$, while the mean flow was between 0.4 and $2.8 \mathrm{~m}$, which represents 0.4 to $3 \%$ of the mean glacier flow of the front. For the measurements at Pynten, the total variation due to radio refractivity was approximately $\pm 6 \mathrm{~mm}$, while the mean measured flow was between 0.4 and $3.0 \mathrm{~m}$, which 
represents 0.2 to $1.5 \%$ of the flow. However, this neither includes the effect of cross-glacier variation in radio refractivity nor other systematic effects. The estimated measurements' uncertainty therefore represents a small portion of the total measured flow.

Calving events could be identified in the high spatially and temporally sampled data set. With the measurement set-up used in 2008, the maximum unambiguous velocity was ca. $1150 \mathrm{~m} /$ day. With that set-up, calving onsets were identified by the accelerating phase in the hours before failure, and in most cases calving could be verified by greatly reduced reflection from the range cell associated with the loss of ice. We know from the 2008 measurements that the red line in Fig. 18 represents a calving event. If we compare this event with the events represented by the blue line in Fig. 12 and the blue and purple lines in Fig. 16, there is a strong indication that we have captured two calving events in the measurements from Ny-Ålesund and one calving event from Pynten. High temporal sampling of data makes it possible to detect calving events and time series thereof, which are useful for glacier dynamics studies and for warning Arctic Ocean ship traffic of icebergs.

Glacier flow measurements show, as expected, the highest velocity in the front of the glacier. This is where the radar measurements with a high temporal rate may have recorded rotational movement of ice blocks. The accumulated flow measured from Pynten is presented in Fig. 11 and for Ny-Ålesund in Fig. 15. The highest flow at the terminus of the glacier is probably due to calving onsets or rotational motion of large portions of ice. We have presented accumulated flow for a period using high temporal resolution data. Our presented terminus velocities may therefore be higher than the average values determined by methods with lower temporal resolution, for example satellite systems.

Comparison of our measurements conducted at Pynten and Ny-Ålesund shows some deviation in the spatial distribution on the glacier of the determined mean flow (Fig. 17). The measurements from Pynten show a mean glacier flow varying from $0.4 \mathrm{~m} /$ day close to Colletthøgda to a maximum of $3 \mathrm{~m} /$ day in the central area, before decreasing to $0.4 \mathrm{~m}$ /day along Kongsvegen, while the measurements from Ny-Ålesund show that the glacier flow varies from $0.4 \mathrm{~m} /$ day close to Colletthøgda to a maximum of $2.8 \mathrm{~m} /$ day in the central area, before decreasing to $0.2 \mathrm{~m} /$ day along Kongsvegen. The mean flow of the first $300 \mathrm{~m}$ of the glacier is 1.66 and $1.72 \mathrm{~m} /$ day from Pynten and Ny-Ålesund respectively. The differences might be due to short observation time, measurements on two different days, or/and different spatial resolution. The glacier cross-range resolution when measuring from Ny-Ålesund is $780 \mathrm{~m}$ and it is
$315 \mathrm{~m}$ from Pynten, and the range-resolution is $5 \mathrm{~m}$ in the measurements from Ny-Ålesund and $2 \mathrm{~m}$ in the measurements from Pynten. This results in a radar footprint of $3900 \mathrm{~m}^{2}$ when measuring from Ny-Ålesund and $628 \mathrm{~m}^{2}$ when measuring from Pynten; hence, the mean values are calculated over different spatial scales. The mean flow calculated from the measurements at Pynten and Ny-Ålesund corresponds well despite the short observation time and different measurement set-ups.

The mean estimated flow of the first $300 \mathrm{~m}$ of the glacier could be used to make a rough estimate of the area lost by calving per day under the assumption of a stable position at the glacier front: the width of Kronebreen is approximately $3.1 \mathrm{~km}$, resulting in a loss of 1.55 to $1.60 \mathrm{~km}^{2} /$ day. These area estimates could be conducted on varying timescales, in this experiment they are down to $11 \mathrm{~s}$. With knowledge of the ice thickness profile of the glacier, the determined velocities could be used to make an estimate of the calving volume of Kronebreen.

A near real-time monitoring system could be optimized for glacier calving studies. An advantage of radars with an electronically steered antenna is their ability to change the angle of view dynamically from pulse to pulse. If we detect accelerating flow, it might be the onset of a calving event and the antenna can be electronically directed to this area for higher resolution temporal mapping. Machine-learning algorithms or statistical signal processing could help automate the identification of calving onsets by recognizing the behaviour prior to a calving event, similar to what is performed on timelapse imagery (Vallot et al. 2018). Steering the antenna towards calving events may be combined with radar monitoring of the whole glacier, but this will cause a trade-off between the temporal rate needed to follow the motion of the calving and the resources needed for continuous monitoring the rest of the glacier. In this study, we used a prototype radar with a $32-\mathrm{cm}$ antenna, giving a cross-range resolution of $3^{\circ}$. After these experiments, ISPAS has produced a new series of radars with $96-\mathrm{cm}$ antennas, which give a $1^{\circ}$ cross-range resolution. These radars would give three times the spatial resolution compared to prototype radar. The temporal resolution during the measurements was also limited to reduce the size of radar data acquired because the radar data had to be processed off-line after the measurements. In a new production model, radar data are processed online in a dedicated field-programmable gate array. Using a full-scale antenna and an angular step-size of half the cross-range resolution $\left(0.5^{\circ}\right)$, this would require 42 steps from Pynten and 24 steps from $\mathrm{Ny}$-Ålesund to map the Kronebreen glacier. The temporal resolution would be 83 images per second and 47 images per second from Ny-Ålesund and Pynten respectively. 
The location of the radar determines the size of the covered measurement area and the spatial resolution. The major returned radar reflections in the measurement scene are from the glacier front. This is due to the shallow angle between the radar waves and the surface of the glacier (Fig. 5). This applies to both Ny-Ålesund and Pynten but is most evident in the measurements from Pynten, where there are little or no reflections in the area close to Colletthøgda (Fig. 9). One way to increase the illumination of the shaded areas of the glacier is to elevate the radar. This might not be practically feasible in the area around Pynten, but in Ny-Ålesund there is infrastructure on the mountain Zeppelinfjellet, just south of the settlement. Locating the radar at Zeppelinfjellet at a height of approximately $480 \mathrm{~m}$ a.s.l., as opposed to $10 \mathrm{~m}$ a.s.l. in Ny-Ålesund, would increase the radar's grazing angle from ca. 0.04 to ca. $1.8^{\circ}$. Elevating the radar will improve the reflections from the up-glacier surface. We inspected the facilities at Zeppelinfjellet and found it suitable for a permanent radar installation. Locating the radar here would facilitate monitoring of the calving fronts of four glaciers: Blomstrandbreen, Conwaybreen, Kronebreen and Kongsvegen. This would make possible comparison of inter-glacial variations in flow speed.

\section{Conclusion}

This study has shown that the tested radar provided an efficient means for monitoring the glacier flow of Kronebreen. Tests were conducted at two locations, 6 and $15 \mathrm{~km}$ from the glacier front, to assess whether increased distance between the radar and the measured object affect the quality of the measured data. The result with the highest special resolution was obtained from the point closest to the glacier front. However, the measured flow speed of the glacier was comparable from both locations. We conclude that reliable glacier flow measurements could be made from both locations.

Changes in radar parameters and temporal rates should be investigated further in connection to coherence and attenuation to improve interferometric calculations and accurate measurements of glacier velocity. The system should be optimized and further developed regarding the real-time data processing and antenna steering.

The new radar tested makes it possible to compare and analyse glacier flow at different temporal and spatial scales. Data with high temporal resolution could be valuable for the dynamic studies of glaciers, while long time series would be useful in the studies of sessional variations in glacier mass balance. Near real-time data from calving fronts may be used for developing more advanced monitoring systems for ship traffic in the Arctic (Notz \& Stroeve 2018), facilitating operations and decision-making during operations at sea. In further studies, the G-B measurements could be combined with spaceborne data to take advantage of the wide-area coverage of space-borne sensor and the high temporal resolution of G-B sensor.

Ny-Ålesund, preferably Zeppelin Mountain, is a wellsuited location for a permanent installation of a glacier monitoring system, as the existing infrastructure at this site would significantly simplify the technical installation and maintenance of the proposed monitoring system. Another benefit is the number of glacier fronts visible from Zeppelin Mountain, allowing one radar to monitor the flow of four glaciers: Kongsbreen, Kronebreen, Conwaybreen and Blomstrandbreen.

\section{Acknowledgements}

The fieldwork was made possible through the Svalbard Science Forum (RiS ID 10878, 2D Velocity Mapping of Glaciers), the Norwegian Polar Institute and Kings Bay AS.

\section{Disclosure statement}

RG and RN work at, own stocks in and are board members of ISPAS AS.

\section{Funding}

This work was supported by the Research Council of Norway.

\section{References}

Baker C. \& Trimmer B. 2000. Short-range surveillance radar systems. Electronics and Communication Engineering Journal 12, 181-191, doi: 10.1049/ecej:20000406.

Bamber J.L., Westaway R.M., Marzeion B. \& Wouters B. 2018. The land ice contribution to sea level during the satellite era. Environmental Research Letters 13, article no. 063008, doi: 10.1088/1748-9326/aac2fo.

Berardino P., Fornaro G., Lanari R. \& Sansosti E. 2002. A new algorithm for surface deformation monitoring based on small baseline differential SAR interferograms. IEEE Transactions on Geoscience and Remote Sensing 40, 2375-2383, doi: 10.1109/TGRS.2002.803792.

Box J.E., Colgan T.C., Wouters B., Burgess D.O., O'Neel S., Thomson L.I. \& Haugaard Mernild J.S. 2018. Global sea-level contribution from Arctic land ice: 1971 to 2017. Environmental Research Letters 13, article no. 125012, doi: 10.1088/1748-9326/aaf2ed. 
Chapuis A., Rolstad C. \& Norland R. 2010. Interpretation of amplitude data from a ground-based radar in combination with terrestrial photogrammetry and visual observations for calving monitoring of Kronebreen, Svalbard. Annals of Glaciology 51, 34-40, doi: 10.3189/1727564107 91392781.

Chen C. \& Zebker H.A. 2002. Phase unwrapping for large SAR interferograms: statistical segmentation and generalized network models. IEEE Transactions of Geoscience and RemoteSensing 40, 1709-1719, doi: 10.1109/TGRS. 2002.802453.

Dematteis N., Luzi G., Giordan D., Zucca F. \& Allasia P. 2017. Monitoring alpine glacier surface deformations. Remote Sensing Letters 8, 947-956, doi: 10.1080/2150704X.2017.1 335905 .

Gundersen R., Norland R. \& Denby C.R. $2018 \mathrm{a}$. Ground-based differential interferometric radar monitoring of unstable mountain blocks in a coastal environment. Remote Sensing 16, article no. 914, doi: 10.3390/ rs 10060914.

Gundersen R., Norland R. \& Denby C.R. 2018b. Geometric, environmental and hardware error sources of a groundbased interferometric real-aperture FMCW radar system. Remote Sensing 10, article no. 20170, doi: 10.3390/ rs 10122070 .

Hanssen R. 2002. Radar interferometry: data interpretation and error analysis. Dordrecht: Kluwer Academic Publishers.

Heinselman P.L. \& Torres S.M. 201 1. High-temporal-resolution capabilities of the national weather radar testbed phasedarray radar. Journal of Applied Meteorology and Climatology 50, 579-593, doi: 10.1175/2010JAMC2588.1.

Kääb A., Lefauconnier B. \& Melvold K. 2005. Flow field of Kronebreen, Svalbard, using repeated Landsat 7 and ASTER data. Annals of Glaciology 42, 7-13, doi: 10.3189/172756405 781812916.

Karamakar P. 2011. Microwave propagation and remote sensing, atmospheric influences with models and applications. Boca Raton, FL: CRC Press.

Kotlyakov V. \& Grosswald M. (eds.) 2008. Effect on individual glaciers on climate. Polar Geography and Geology 14, 217-240, doi: 10.1080/10889379009377433.

Lefauconnier B., Hagen J.O. \& Rudant J.P. 1994. Flow speed and calving rate of Kongsbreen glacier, Svalbard, using SPOT images. Polar Research 13, 59-65, doi: 10.3402/polar. v13il.6681.

Levanon N. 1988. Radar principles. Tel Aviv: John Wiley \& Sons. López-Moreno J., Alonso-González E., Monserrat O., Del Río L., Otero J., Lapazaran J., Luzi G., Dematteis N., Serreta A., Rico I., Serrando-Canadas E., Bartolome M., Moreno A., Buian S. \& Revuelto J. 2018. Groundbased remote-sensing techniques for diagnosis of the current state and recent evolution of the Monte Perdido Glacier, Spanish Pyrenees. Journal of Glaciolog 65, 85-100, doi: 10.1017/jog.2018.96.

Luckman A., Benn D.I., Cottier F., Bevan S., Nilsen F. \& Inall M. 2015. Calving rates at tidewater glaciers vary strongly with ocean temperature. Nature Communications 6, article no. 8566 , doi: 10.1038/ncomms 9566 .
Moon T., Ahlstrøm A., Goelzer H., Lipscomb W. \& Nowicki S. 2018. Rising oceans guaranteed: Arctic land ice loss and sea level rise. Current Climate Change Reports 4, 211-222, doi: 10.1007/s40641-018-0107-0.

Noferini L., Mecatti D., Macaluso G., Pieraccini M. \& Atzeni C. 2009. Monitoring of Belvedere Glacier using a wide angle GB-SAR interferometer. Journal of Applied Geophysics 68, 289-293, doi: 10.1016/j.jappgeo.2009.02.004.

Notz D. \& Stroeve J. 2018. The trajectory towards a seasonally ice-free Arctic Ocean. Current Climate Change Reports 4, 407-416, doi: 10.1007/s40641-018-0113-2.

Rignot E., Hallet B. \& Fountain A. 2002. Rock glacier surface motion in Beacon Valley, Antarctica, from synthetic-aperture radar interferometry. Geophysical Research Letters 29, article no. 1607, doi: 10.1029/2001GL013494.

Rolstad C. \& Norland R. 2009. Ground-based interferometric radar for velocity and calving-rate measurements of the tidewater glacier at Kronebreen, Svalbard. Annals of Glaciology 50, 47-54, doi: 10.3189/1727564097877 69771.

Scambos T.A., Bell R.E., Alley R.B., Anandakrishnan S., Bromwich D.H., Brunt K., Christiansen K., Creyts T., Das S.B., DeConto R., Dutrieux P., Fricker H.A., Holland D., MacGregor J., Medley B., Nicolas J.P., Pollard D., Siegfried M.R., Smith A.M., Steig E.J., Trusel L.D., Vaughan D.G. \& Yager P.L. 2017. How much, how fast?: a science review and outlook for research on the instability of Antarctica's Thwaites Glacier in the 21 st century. Global and Planetary Change 153, 16-34, doi: 10.1016/ j.gloplacha.2017.04.008.

Schellenberger T., Dunse A., Kääb A., Kohler J. \& Reijmer C. 2015. Surface speed and frontal ablation of Kronebreen and Kongsbreen, NW Svalbard, from SAR offset tracking. The Cryosphere 9, 2339-2355, doi: 10.5194/ tc-9-2339-2015.

Strozzi T., Werner C., Wiesmann A. \& Wegmüller U. 2012. Topography mapping with a portable real-aperture radar interferometer. IEEE Geoscience and Remote Sensing Letters 9, 277-281, doi: 10.1109/LGRS.2011.2166751.

Vallot D., Adinugroho S., Strand R., How P., Pettersson R., Benn D.I. \& Hulton N.R. 2018. Automatic detection of calving events from time-lapse imagery at Tunabreen, Svalbard. Geoscientific Instrumentation, Methods and Data Systems 8, 113-127, doi: 10.5194/gi-2018-5.

Voytenko D., Dixon T.H., Holland D.M., Cassotto R., Howat I., Fahnestock M.A., Truffer M. \& De la Peña S. 2017. Acquisition of a $3 \mathrm{~min}$, two-dimensional glacier velocity field with terrestrial radar interferometry. Journal of Glaciology 63, 629-636, doi: 10.1017/jog.2017.28

Voytenko D., Dixon T., Werner C., Gourmelen N., Howat I., Tinder P. \& Hooper A. 2012. Monitoring a glacier in southeastern Iceland with the portable terrestrial radar interferometer. In: 2012 IEEE International Geoscience \& Remote Sensing Symposium proceedings. Pp. 3230-3232. Piscataway, NJ: Institute of Electrical and Electronics Engineers, doi: 10.1109/IGARSS.2012.6350736.

Werner C., Strozzi T., Wiesmann A. \& Wegmüller U. 2008. A real-aperture radar for ground-based differential 
interferometry. In: 2008 IEEE International Geoscience $\theta$ Remote Sensing Symposium proceedings. Pp. 210-213. Piscataway, NJ: Institute of Electrical and Electronics Engineers, doi: 10.1109/IGARSS.2008.4779320.

Xie S., Dixon T., Voytenko D., Deng F. \& Holland D. 2018. Grounding line migration through the calving season at Jakobshavn Isbræ, Greenland, observed with terrestrial radar interferometry. The Cryosphere 12, 13871400, doi: 10.5194/tc-12-1387-2018.

Zebker H., Rosen P. \& Hensley S. 1997. Atmospheric effects in interferometric synthetic aperture radar surface deformation and topographic maps. Journal of Geophysical Research-Solid Earth 102, 7547-7563, doi: 10.1029/96JB03804. 